\title{
Social media mining for BIM skills and roles for energy efficiency
}

\author{
Andrei Hodorog, Ali Hussain S Alhamami, Ioan Petri, \\ Yacine Rezgui \\ Cardiff School of Engineering \\ Cardiff University \\ Cardiff, United Kingdom \\ hodoroga@ cardiff.ac.uk
}

\begin{abstract}
Information modelling for the construction industry can address the fragmentation, multitude of professions and companies that often require collaboration and data exchange. Construction projects involve various professions, including design teams, contractors, facility managers, product manufacturers and suppliers, user associations, clients and investors, and local/regional/national/international authorities. The increasing complexity of buildings is reflected in the continuous introduction of new procurement paths and methods, construction technologies, materials and construction methods to meet various economic, environmental and societal challenges. To address this level of complexity Building Information Modelling (BIM) can create synergies and support collaboration not only between traditional disciplines and roles (architecture, structure, mechanical and electrical), but also support many new professions and skills in areas such as energy, environment, waste and connected objects / Internet of Things.
\end{abstract}

In this paper, we explore the dynamic nature of BIM with associated skills and roles and demonstrate how engagement and training can be informed by social media analysis to identify roles, skills and training needs. We conduct a data mining process by analysing the Twitter data of various companies and institutions involved in the BIM construction sector to discover new skills and roles for energy efficiency.

Keywords - Building Information Modelling; Social Media, Analysis, BIM skills and roles; Training; Energy Efficiency

\section{INTRODUCTION}

The increasing complexity of buildings is mirrored by the advent of new procurement paths and methodologies, construction technologies, materials and construction methods to meet various economic, environmental and societal challenges. This requires the involvement of not only traditional disciplines and roles (architecture, structure, mechanical and electrical, etc.), but also many new professions and skills in areas such as energy, environment, waste and connected objects / Internet of Things. For instance, designing a hospital requires not only meeting tighter energy and carbon requirements but also drastically reducing infection rates through the adaptation of architectural design.

Prior to the introduction of IT, and up to the early 1980s, the main concern of the construction industry was project data and information management [1], [3]. As a large construction project may eventually result in the production of tens of thousands of documents, the concern

\author{
Sylvain Kubicki, Annie Guerriro \\ Luxembourg Institute of Science and Technology \\ Luxembourg, Luxembourg \\ sylvain.kubicki@list.lu
}

of the industry was to provide easy and quick means to identify and locate the appropriate document [4]. This relied mainly on managing project documentation either on an ad-hoc basis or at best using traditional library archival methods. Documents were text-based and graphical information and knowledge carriers often shared in paper forms. Central to the idea of a document is the fact it can be easily transferred, stored and handled as a unit $[2,3]$. Project documents have remained similar for the last decades. Drawings (plans, sections, elevations, etc.) and text-based documents (bills of quantities, specifications, etc.) look similar regarding contents and form. However, the process involved in producing, distributing/sharing, approving, and updating these documents has evolved following the introduction of Information Technologies [3]. The current situation in the construction sector represents a mix of different document management methods [4, 5]. Initial document management systems used basic file management capabilities found in operating systems, and included many functionalities [5] including user authentication; the main retrieval mechanism based on either hierarchical folders or metadata; handling of revisions and change management; viewing of proprietary files using their native software; full-text search capability. In a nutshell, documents are stored centrally on a server and users interact with this central repository through simple interfaces and then later on with the advent of the Internet, through using simple web browsers.

Within the last decade, researchers and commercial application developers in the construction domain have started to develop tools to manipulate complex building models [6]. By storing and managing building information as databases, BIM (building information modelling) solutions can capture, manage, and present data in ways that are appropriate for the user of that data. Because the information is stored in a logically centralised database, any changes in building information data can be logically propagated and managed by software throughout the project life cycle [7, 8]. Building information modelling solutions add the management of relationships between building components beyond the object-level information in object-oriented CAD solutions. This allows information about design intent to be captured in the design process. The building information model contains not only a list of 
building components and locations but also the relationships that are intended between those objects [9].

BIM is commonly defined as the process of generating and managing data and information about a building during its entire life cycle from concept design to decommissioning [10]. Industry Foundation Classes [11] are a commonly used form for BIM. They are open data model specifications for defining building components' geometry and other physical properties in a way that enable CAD users to transfer design data between different software applications [10, 12]. They are intended to provide an authoritative semantic definition of building elements, their properties and inter-relationships. Data associated with IFC can include textual data, images (such as building schematics); structured documents, numerical models and designer/project manager annotations. The IFC specification is developed and maintained by BuildingSmart and has been included in several ISO standards. The IFC with its standard set of rules for data storage, data exchange and protocols provides an ideal framework to manage data related to a building throughout its life-cycle.

Some semantic resources and information management standards have been developed for the construction domain. These include COBie (Construction Operations Building Information Exchange), agcXML, and BS1192:2007. COBie is developed as a standard data specification for structured information exchange [13]. The COBie approach and concept is to input data and information during the processes of design, construction, and commissioning, which will support the operations, maintenance, and the management of the facilities by the owner and facilities manager. It provides traceability and visibility of design, construction and handover information and decisions. AgcXML, a buildingSMART project as part of the aecXML Domain framework, aims at producing a set of eXtensible Markup Language (XML) schemas of structured format for the exchange of information during the design and construction process through any number of documents including the request for information and change orders amongst others [14]. BS1192:2007 is a standard for the collaborative production of project information which provides a naming convention constructed using specific metadata fields. These standards complement the IFC development efforts and are a good contribution towards addressing some of the BIM shortcomings.

This paper presents a methodology for identifying roles, skills and training needs in the field of BIM for energy efficiency. We use social media analysis in a repository of Twitter records for capturing emerging skills and roles in the field of BIM. The analysis was facilitated by the use of a semantic BIM training portal that aggregated content from different BIM related data sources. Following this introduction, Section II provides a review of relevant literature. Section III provides an overview of a BIM training platform. Section IV presents the methodology used in the research approach. Section $V$ introduces a discussion about the difficulties encountered and future work. Section VI provides concluding remarks and directions for future research.

\section{LITERATURE REVIEW}

In this section, we explore related works from the field of BIM with particular emphasis on roles and skills to inform the training programmes.

BIM has been validated as an efficacious method for construction projects and can have a significant impact on quality, resource efficiency, and reduction in construction time and cost [15]. Research studies [16] have shown tangible benefits of BIM in projects. BIM can be used for various purposes throughout the project life-cycle, and increase productivity. Since BIM relates to products, processes as well as people, the BIM way of working requires active collaboration and communication between the project participants. Team members from different disciplines need to work with BIM data, supported by BIM professionals. BIM tools provide various possibilities for collaboration and exchange of data. A dedicated BIM manager for the projects is often considered a requirement today. Thus, active cooperation between stakeholders is critical to successful BIM implementation.

Consequently, BIM education has become one of the key requirements in Architecture Engineering and Construction (AEC) education. BIM can empower the current and future AEC professionals to accomplish an increase in productivity, waste reduction, and creation of a sustainable future through a combination of technical, methodological, procedural and organisational skills and competencies. Thus, BIM education should also include individual as well as team skills and competencies [17]. Nonetheless, because BIM is a relatively new topic in AEC education, and because the best practices in BIM education are yet to emerge, BIM courses are often taught as technology training without any theory or collaborative learning. In contrast, industry values both technical and collaborative skills, as the base for better integration and growth of future employees.

\section{A. ICT and BIM}

Information and Communication Technologies (ICTs) have been recognised as a key player for reducing energy consumption and to move forward to a more sustainable and smart society [18]. The building sector is responsible for $40 \%$ of energy consumption and $36 \%$ of $\mathrm{CO} 2$ emission in Europe [19]. As 35\% of existing buildings are over 50 years old, increasing their energy efficiency could reduce energy usage from 5\% to 6\% and $\mathrm{CO} 2$ emissions by about $5 \%$. Recent improvements in ICTs offer an archipelago of devices, software and communication paradigms that can enable the deployment of real smart-buildings and cities 
[20]. Devices, such as low-power Wireless Sensor Networks (WSNs) for environmental monitoring, and novel smart meters for electric load profiling and recognition, give the possibility of monitoring and characterisation of energy consumption behaviour of buildings and dwellings [28].

Individual BIM competencies are actually the personal traits, technical abilities and professional knowledge needed by a person to do a BIM activity or even to provide a BIM related outcome. These capabilities, outcomes or activities should be measurable against performance criteria and could be acquired or even enhanced through development, training, and education [21].

Several authors highlight the need for BIM skills in the AEC industry. For example, Mohd and Ahmad Latiffi [22] mention that skilled BIM workforce helps in achieving cost reduction and improved time management through clash detection.

$\mathrm{Wu}$ and Issa [23] anticipate BIM education as a solution to brisk up the BIM learning to curve, although they recognise that competencies of fresh graduates are not enough to satisfy the work-related demand. Instead, they suggest that BIM education should prepare graduates to be ready to the extent that the organisations can shape BIM competencies of these graduates as per their own need.

Yarmohammadi and Ashuri [24] emphasise BIM competence regarding the coordination of building services, and how, a team leader with high BIM competence can have a major impact on the progress and coordination of the project. The construction industry prefers to have future employees with deep conceptual knowledge of BIM rather than those with BIM application skills only.

A growing trend of new positions including BIM professor and BIM manager shows the increasing need for BIM competent workforce. Project managers are likely to have a role as BIM managers. However, Rahman et al. [25] state that skill sets needed for project managers and the BIM managers are different. The authors also highlight skills like teamwork and communication are required in the curricula. Dossick et al. [26] emphasise that BIM curriculum should also include the understanding of computer application concepts and BIM processes. Barison et al. [27] look into individual competencies including aptitude, qualifications, skills/abilities, knowledge and attitude, noting the professional need for the position in both foundational and functional ways.

\section{B. BIM training approach to EU-wide impact}

The paragraph above shows the complexity of the challenges facing the construction industry: increasing pressure from regulations requiring significant energy efficiency gains; increased economic pressures and competition; and dramatic developments in working culture and practices. A gamechanging factor which would support the transition to more energy-efficient practices is clearly needed.

Information and Communication Technologies (ICT) can play this game-changing role, by enabling for faster and more reliable design decision-making and construction follow-up [29]. BIM, at first, has proven to provide for the enhancement of design support (through 3D visualisation, physical simulation, upstream assessment of design options) and construction planning and monitoring (construction phasing and continuous monitoring)[30]. Such advanced support from digital tools is likely to allow for significant improvements of the quality and performance of buildings [31], as well as for time and cost-savings to preserve the competitiveness of European businesses. Based on the rationale elaborated above, the main objectives for BIM engagement and training are to leverage the take-up of ICT and Building Information Modelling technologies through a significant upgrade of the skills and capacities of the European Construction workforce, to dramatically improve the reliability and effectiveness of design and construction practices, with a view to achieve the objectives of the Energy Union. ICT methods are utilised to create a dynamic and open community of users that can share experiences and contribute to the process of training and education for BIM in energy efficiency.

\section{BIM Training and ICT}

Digital systems are drastically altering the way of working and consequently call for the workforce to create suitable skills to fully gain from the chances opened up by the digitalisation of this building industry. Considerable work is, therefore, being invested with the EU Member States to develop strategies and programmes that seek integrating the usage of digital resources, and especially $\mathrm{BIM}$, in the construction process.

The majority of Member States introduced national strategies to cultivate the promotion and adoption of BIM by the construction industry. Many consist of action plans that entail an element of R\&D, development of BIM standards and the set-up of working groups and task forces of stakeholders and experts to exchange the best practices and expertise. Such techniques are usually broader in scope as well as, though they recognise the benefits of instruction, they don't specifically concentrate on the definition of instruction initiatives, on revitalising the uptake of BIM along with knowledge sharing, thus offering a common direction as well as the original framework for the subsequent construction of dedicated knowledge and training schemes. 
The most prominent examples can be found in countries like Denmark and Germany, where using BIM is even compulsory under certain conditions. Indeed, Denmark was an early adopter of BIM, with its implementation in public construction projects being mandated as of 2007. Moreover, as of 2013, BIM is also mandatory for projects that are fully and partially funded by the government and that exceed DKK 5 million (EUR 672,300) [32]. Similarly, in Germany, the Federal Ministry of Transport and Digital Infrastructure announced that BIM would be made compulsory on all transport projects by 2020, whereas the German BIM Steering Group 'Planen Bauen 4.0' aims to set clear guidelines for the practical application of BIM methods by introducing the BIM Level Plan (Stufenplan fur BIM in Deutschland. Such strategies are meant to raise awareness of BIM among relevant actors and address key questions including the roles and responsibilities of each actor (what data must be provided by whom, what the expectations are, etc.). Indeed, as part of this initiative, the establishment of a national BIM Competence Centre is foreseen, where the findings and experiences on the use of digital planning methods will be gathered into a new central point of contact [33].

\section{A BIM TRAINING PlatFORM}

The BIMEET project portal (energy-bim.com) brings together nine partners around BIM technology as key digital support for the energy efficiency of the built environment. The participants include Luxembourg Institute of Science and Technology (LIST), Cardiff University, Centre Scientifique et Technique du Bâtiment (CSTB), Building Research Establishment Ltd (BRE), La plateforme Formation \& Évaluation de l'INES, VTT Technical Research Centre of Finland Ltd, House of Training, Metropolia University of Applied Sciences and Center For Renewable Energy Sources (CRES).

This platform has helped in the process of BIM training requirements for energy efficiency but also aims at solving the key issue of knowledge dissemination in, and stakeholder engagement with, BIM practices and construction. The objective is to identify gaps and requirements as an initial phase but also to support with the project implementation phase in providing construction professionals with the necessary training to offer effective BIM expertise for energy efficient and low carbon solutions, while also enabling them to utilise the latest best practice and regulations.

This web-based platform provides integrated access to BIM Resources in the form of interactive, dynamic and user-oriented services that take full advantage of the latest technology advances. The platform is an open, scalable, polymorphic context-based solution with modules which allow the use of a symbiosis of technology to unlock information and knowledge [29].
As part of the platform, we have implemented a search service that performs semantic searching on the platform BIM knowledge base from a set of authoritative URIs. The submitted BIM query has a set of associated ontological concepts for improving the precision and the recall of the returned results. The search service also provides an aggregation of data from a variety of trusted sources related to BIM via web-crawling. These sources can be proposed by users and validated by a group of experts according to their relevance to BIM for energy efficiency. The list of these sources can be seen below:

http://www.bim.psu.edu

http://digitalbuilding.lu

http://www.list.lu

http://objectif-bim.com

http://www.batiment-numerique.fr

http://www.accept-project.com

http:///construction21.org

http://bimcrunch.com

http://mediaconstruct.org

http://bimblog.house

http://geometrygym.wordpress.com

http://cardiff.ac.uk

http://www.ines-solaire.org

http://eksergia.fi

http://buildingsmart.fi

We have also implemented a Professional Networking Service that enables users to collaborate using social networks such as LinkedIn and Twitter by aggregating associated data. This service also allows users to search for partners and colleagues and identify the corresponding networking profiles based on a set of BIM interests and disciplines.

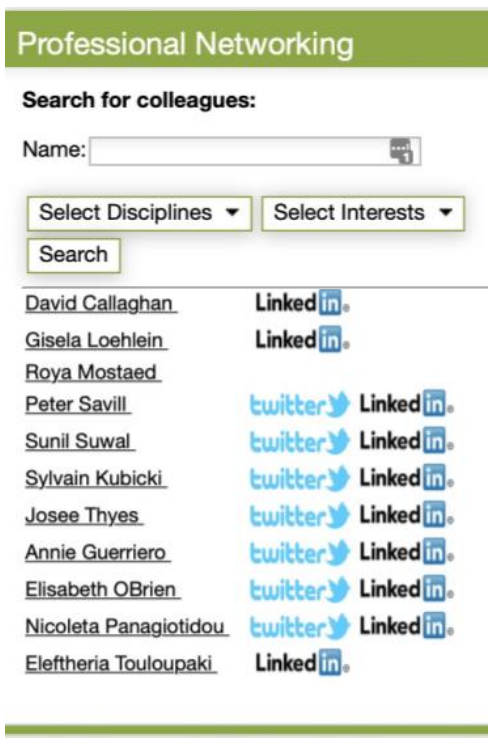

Fig. 1.Professional networking service

An Events Calendar Service is used as a reminder of the important BIM events from the engineering 
community. Users can subscribe and synchronise these events relating to sustainability with their personal calendar.

A BIM Tools Service will be implemented to expose a number of BIM tools addressing various aspects of energy such as carbon emissions, energy simulation, etc.

A BIM Training Service will be implemented in the next steps of the project, enabling users to identify courses and lectures related to BIM for energy efficiency in construction from various institutions such as universities, research organisations, governments agencies etc.

Within the energy-bim.com platform the query and expand methods are exposed to provide the key use of the ontology, which is to drive the search engine. Firstly, the terms within the ontology are used to provide keyword suggestions when entering search terms (using the query method). Secondly, the relationships between terms are used to help users expand/restrict their queries based on suggestions from the ontology (as observed in Fig. 2).

\begin{tabular}{|c|c|}
\hline building information modelling bim & Refine Search \\
\hline Recent searches (clear): bulling intormation model & $\begin{array}{l}\text { Refine your search for.building } x \\
\text { information modelling bim }\end{array}$ \\
\hline Event Calendar & ๑匹 Building Modeling \\
\hline Searching for building information modelling bim & Refine Search \\
\hline $\begin{array}{l}\text { Back } \\
\text { View Full Results } \\
\text { - LCRI Urban Scale Modelling Road Show } \\
\text {.... Carbon Buildings Cymru' will launch the SAP... be grateful if you c }\end{array}$ & $\begin{array}{l}\text { SubSearch within your search: } \\
\text { building information modelling } \\
\text { bim } \\
\text { Additional Search Terms: }\end{array}$ \\
\hline $\begin{array}{l}\text { - LCRI Urban Scale Modelling Road Show } \\
\text {...... Carbon Buildings Cymru' will launch the SAP... would be grateful }\end{array}$ & Search \\
\hline
\end{tabular}

Fig. 2. The platform search system

The innovative dimension of the energy-bim.com platform lies in its open, scalable and polymorphic context-based widgets that reconfigure and update themselves to respond to changing user context and (BIM related) queries while enabling serendipitous BIM information and knowledge discovery. Each service has a corresponding widget that can be updated and administered remotely by users. The analysis of users' statistics and comments helped to identify some key issues to be addressed in future releases of the platform.

We have exposed the energy-bim.com platform as an online location for creating a community of users in the filed on BIM training for energy efficiency. From the monitoring interval between December 2017-February 2018 we have attracted new users and identified an increased number of visits. Using the Woopra analytics illustrated in Fig. 3 below, we were able to collect several statistics on the platform web activity. Fig. 3 illustrates the total amount of visits of the energy-bim.com platform over a trial period of 3 months. It can be identified that popular services and the associated accessed content are related to different countries in Europe.

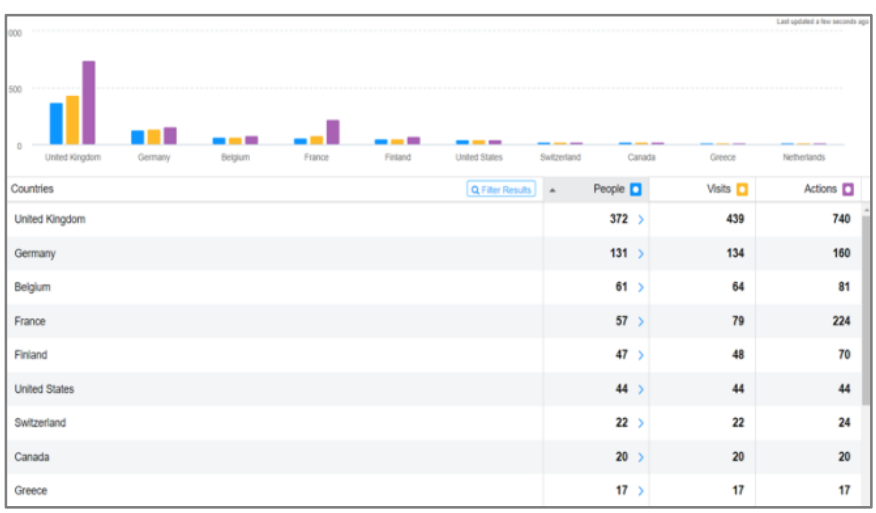

Fig. 3. Statistics for energy-bim.com web activity

Regarding the online activity of access BIM resources, Fig. 4 illustrates the fact that a significant percentage of the users have returned to conduct web searching for BIM resources. Analysing the visitors' geographical provenience, we have identified that the platform presents interest not only of UK visitors but also for US or other EU countries.

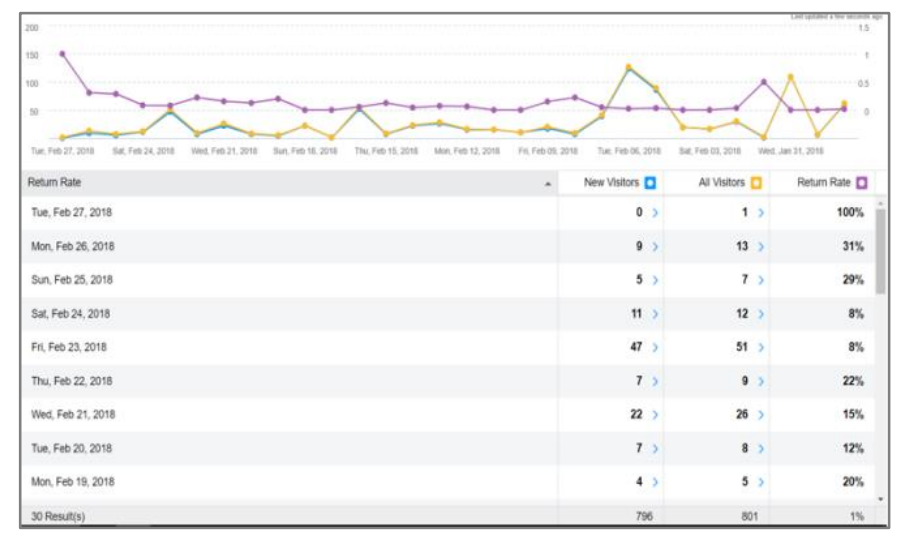

Fig. 4. Returning visitors and visits for energy-bim.com

Initial statistics indicate that the proposed web portal (a) has the potential to engage further practitioners in the delivery of BIM interventions as provided by our work on portal validation; (b) it contributes to the ongoing discussion and integration of BIM in the field of energy efficiency. In addition, technological diversity can contribute to the emergence of new business models and help online marketplace development for the construction industry. We are continuously developing an effective and easy-to-use BIM training platform for the energy sector in order to improve the energy-bim.com platform to refine the search and display of results and online support and interface features. To conduct Twitter analysis, we have aggregated content utilising the energy-bim.com web platform, based on which skills and roles have been identified. We have then used the roles and skills identified as an input to our research described in the next section. 


\section{METHODOLOGY}

The methodology consists in a mixed-method type of research undertaken using additional heuristic content analysis for determining roles and skills based on the portfolio of social media content. This research leverages on the concept of exploring data types including text and social media content to understand dependencies and associations between BIM for energy-related concepts primarily related to roles and skills.

\section{A. Heuristic content mining and expression analysis:}

Due to the noisy nature of social media, where short, informal spelling and grammar are often used, we developed a set of regular expressions (RegEx) and pattern matching rules.

The entire analysis process and methodology has been supported by using the energy-bim.com web platform with objectives for determining roles and skills with corresponding relationships. The web presence of the portal was monitored for a period of 6 months. By utilising forensics methods, a portfolio of companies and users that activate in the field of BIM was identified. Social media profiles of these companies have been identified and content produced by these companies has been collected and analysed with the objective of creating a comprehensive list of roles and skills. For elaborating the list of roles and skills, the following steps have been followed (illustrated in summary in Fig. 5):

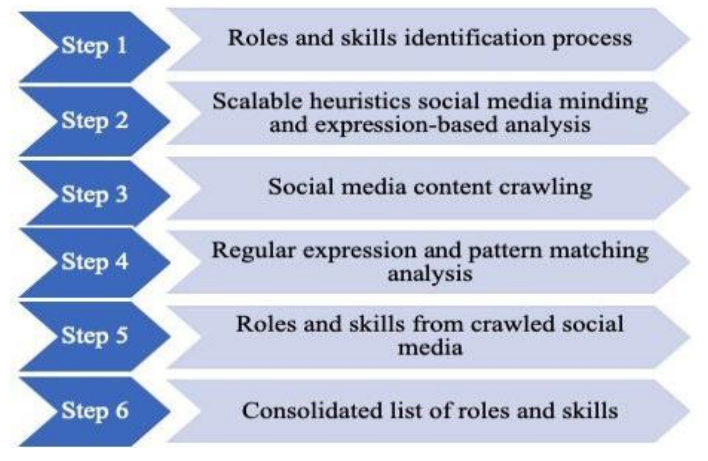

Fig. 5. Twitter analysis process

Step 1: Consolidation of the energy-bim.com portal and monitoring of the web activity including visits and accessed content;

Step 2.1: Configuring and preparation of PHP scripts, a MySQL database and Twitter API for running the collection process;

Step 2.2: Scalable heuristic social media source identification and content consolidation;

Steps 3.1 - 3.4: Preparation of the content to analyse (shortlisting Twitter accounts);

Step 3.5: Implementation of automated crawling techniques from twitter based on several identified twitter accounts which resulted in more than 40 million tweets repository.

Step 4.1 - 4.4: Apply analytics algorithms and mining methods on the consolidated content for skills and roles identification.

Step 4.5: Implementation of expressions and pattern matching algorithms to be applied to the consolidated content.

Step 5.1 - 5.5: Roles and skills identification with associated interests and key directions in the field of BIM for energy as resulted from interviews, use-cases, scientific publications and social media content analysis.

Step 6: Consolidation of the skills and roles complete list relevant for BIM for energy domain.

Step 7: Produce the resulting data

\section{B. Social Media Analysis}

Social media analysis has been conducted by capturing the Twitter activity of the identified company profiles. In this part, only tweets posted by a company have been used and analysed while an extension of this analysis has been provided within the scalable heuristic social media analysis section. In total, for this phase of analysis, we have utilised 40 million tweets posted by the portfolio of companies presented in Table I.

TABLE I. LIST OF THE ORGANISATIONS: TWITTER ACCOUNT AND NAME

\begin{tabular}{|l|l|}
\hline Twitter account & Organisation \\
\hline https://twitter.com/groupecesi & Group CSI \\
\hline https://twitter.com/ines_solaire & INES Solaires \\
\hline https://twitter.com/BREAcademy & BRE Academy \\
\hline https://twitter.com/EcoledesPonts & Ecoles des Ponts ParisTech \\
\hline https://twitter.com/estpparis & ESTP Paris \\
\hline https://twitter.com/universiteliege & Universite de Liege \\
\hline https://twitter.com/uclouvain_be & Université Catholique de \\
& Louvain \\
\hline https://twitter.com/cittadimodena & Citta di Modena \\
\hline https://twitter.com/orsys & ORSYS Luxembourg \\
\hline https://twitter.com/becpartners & BEC \\
\hline https://twitter.com/MiddlesexUni & Middlesex University \\
\hline https://twitter.com/houseoftraining & House of Training \\
\hline https://twitter.com/SapienzaRoma & Sapienza Universita \\
\hline https://twitter.com/master_pesenti & Scuola Pesenti \\
\hline https://twitter.com/le_moniteur & LeMoniteur \\
\hline https://twitter.com/DTUtweet & Technical University of \\
& Denmark \\
\hline https://twitter.com/ntnu & Norwegian University of \\
& Science and Technology \\
\hline https://twitter.com/uicbarcelona & UIC Barcelona \\
\hline https://twitter.com/mumdach & Mensch und Maschine \\
\hline https://twitter.com/ziguratdigital & Zigurat Digital \\
\hline https://twitter.com/bimeetEU & BIMEET EU \\
\hline https://twitter.com/H2020EE & H2020 EE \\
\hline https://twitter.com/H2020BIMplement & H2020 BIMplement \\
\hline https://twitter.com/ECTPSecretariat & ECTP Secretariat \\
\hline https://twitter.com/bsuccar & BSUC Car \\
\hline https://twitter.com/BIMeInitiative & BIMeInitiative \\
\hline https://twitter.com/EU_BUILDUP & EU BUILDUP \\
\hline
\end{tabular}


The list of the organisations utilised for the capturing process has been obtained from three sources: (i) forensics algorithms for IP detection and organisation identification, (ii) followers of the @BIMEET twitter account and (iii) partners indication of known BIM training institutions.

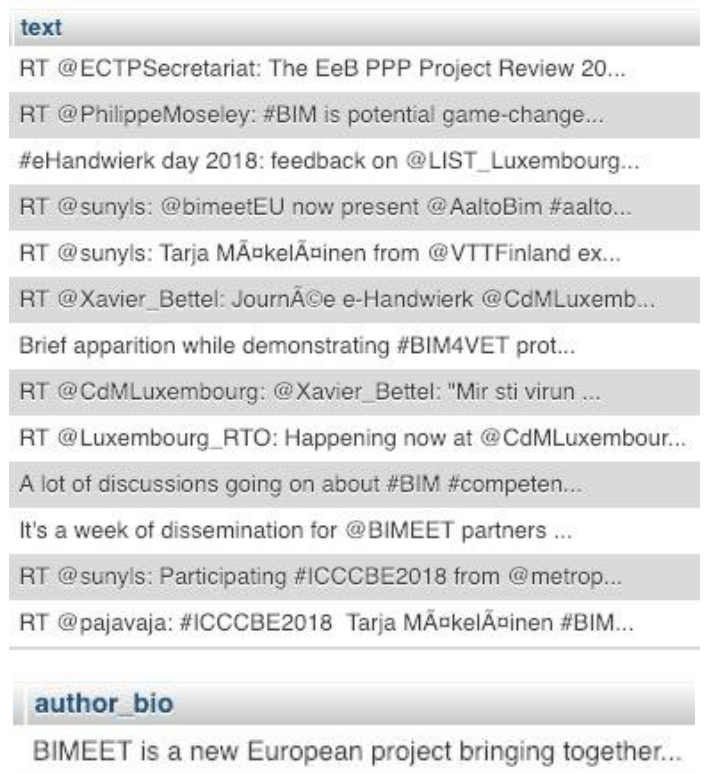

Fig. 6. An excerpt from the collected tweets database

Fig. 6 above illustrates an excerpt from the MySQL database where the collected tweets were stored. We can observe the fields that were analysed for identification of new roles and skills: the tweet text (containing the text of each tweet) and the author_bio (the biography text of the corresponding author).

\section{Expression-based social media analysis}

We have used forensics algorithms to determine what companies, organisation and users from the field of BIM and energy are visiting the energy-bim.com platform. We have recorded all the statistics and based on the list of visitors we have selected profiles of the most relevant companies that activate in the field of BIM for energy efficiency. We have identified other key twitter profiles and followers relevant for our analysis from the twitter followers list of @ BIMEET project (see Table I above).

In the analysis, the following sequence of steps has been applied:

Step 1: Fetching friends and followers from the list of twitter accounts (using the friends_ids and followers_ids twitter APIs, a process detailed in Fig. 7);

Step 2: Fetching timeline tweets from all the friends and followers determined at step 1 using the $u$ ser_timeline twitter API;
Step 3: Importing all the tweets collected at Step 2 in a MySQL database during collection;

Step 4: Querying the SQL database using the regular expressions presented in the list below;

Step 5: Exporting the SQL results in Excel format;

Step 6: Generating word clouds and word trees;

Step 7: Consolidating the final list of roles and skills.

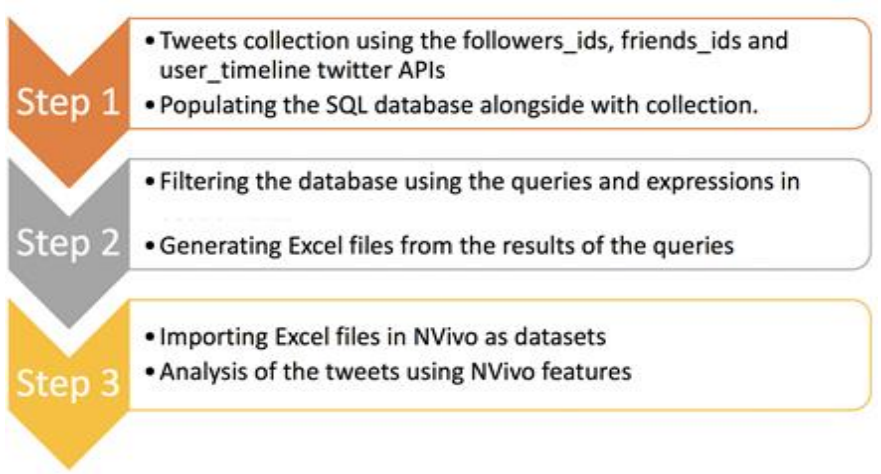

Fig. 7. The process for tweets collection

We have fetched a total of 40 million tweets with text associated and description based on which we conduct text analysis and expression mining for determining skills and roles for BIM for energy efficiency. The set of expression utilised to determine skills and roles are presented below:

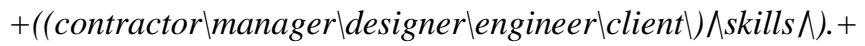

$$
\begin{aligned}
& \text { (Nenergy/\construction) } \\
& +((\text { BIM Mconstruction \energy }) \wedge \text { skills } \Lambda) .+(\text { need/\require })
\end{aligned}
$$

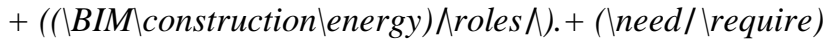

$$
\begin{aligned}
& +((\text { BIM Monstructionlenergy) Nactors } \Lambda) .+(\text { skills / } \\
& \text { \ompetencies) } \\
& \text { + ((BIM Monstruction \energy)Nknowledge }) .+ \\
& \text { (vequirements/ } \text { require) } \\
& +((\text { BIM Mconstruction \energy }) \wedge \text { skills } \Lambda) .+(\text { need/ } \backslash \text { require })
\end{aligned}
$$

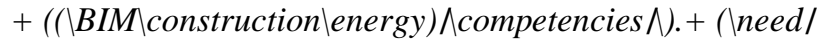

$$
\begin{aligned}
& \text { vrequire) } \\
& \text { + ((skills\competenciesknowledgelexpertise) }(B I M \wedge) .+ \\
& \text { (入energy/\construction) }
\end{aligned}
$$

The regular expressions included are built around the concepts of skills and roles. The main objective was to create an expression for filtering the inaccurate twitter context before analysis of skills and roles. A keyword such as 'construction', 'skills', 'energy' was frequently associated with roles whereas terms such as 'training' and 'knowledge' were more likely to be included in tweets where a skill or role is reported (see Table II).

TABLE II. CONSOLIDATED LIST OF ROLES AND SKILLS FROM TWITTER DATA

\begin{tabular}{|l|l|l|l|l|}
\hline No. & Roles & & No. & Skills \\
\cline { 1 - 1 } \cline { 4 - 5 } & Architect & & $\begin{array}{l}\text { BIM education program } \\
\text { management skills }\end{array}$ \\
\hline
\end{tabular}

2019 IEEE International Conference on Engineering, Technology and Innovation (ICE/ITMC) 


\begin{tabular}{|c|c|c|c|}
\hline 2 & Energy manager & 2 & $\begin{array}{lcc}\text { Certified skills } & \text { through } \\
\text { certification schemes } & \\
\end{array}$ \\
\hline 3 & $\begin{array}{l}\text { Construction } \\
\text { information } \\
\text { manager }\end{array}$ & 3 & Good communication \\
\hline 4 & BIM manager & 4 & $\begin{array}{l}\text { Skills acquired through public } \\
\text { awareness campaigns of the BIM } \\
\text { industry }\end{array}$ \\
\hline 5 & $\begin{array}{l}\text { Digital } \\
\text { technology } \\
\text { designer } \\
\end{array}$ & 5 & $\begin{array}{l}\text { Training for energy efficiency } \\
\text { acquired skills }\end{array}$ \\
\hline 6 & Facility manager & 6 & $\begin{array}{l}\text { Build up energy efficiency in } \\
\text { construction adoption skills }\end{array}$ \\
\hline 7 & Designer & 7 & E-learning acquired skills \\
\hline 8 & Energy expert & 8 & $\begin{array}{lll}\begin{array}{l}\text { Construction } \\
\text { practical skills }\end{array} & \text { supply } & \text { chains } \\
\end{array}$ \\
\hline 9 & Project manager & 9 & $\begin{array}{l}\text { Skills and knowledge needed to } \\
\text { ensure building and renovation } \\
\text { projects meet stringent energy } \\
\text { efficiency requirements }\end{array}$ \\
\hline 10 & $\begin{array}{l}\text { Construction } \\
\text { manager }\end{array}$ & 10 & $\begin{array}{l}\text { Scientific skills and technical } \\
\text { knowledge in the field of } \\
\text { communication concerning } \\
\text { sustainability }\end{array}$ \\
\hline 11 & $\begin{array}{l}\text { Energy efficiency } \\
\text { expert }\end{array}$ & 11 & $\begin{array}{l}\text { Energy efficiency skills } \\
\text { certification scheme for EU }\end{array}$ \\
\hline 12 & $\begin{array}{l}\text { Human resource } \\
\text { manager }\end{array}$ & 12 & Cooperation skills \\
\hline 13 & Team manager & 13 & Modelling skills \\
\hline 14 & Researchers & 14 & Digital skills \\
\hline 15 & Water manager & 15 & Sustainability skills \\
\hline 16 & $\begin{array}{l}\text { Structure } \\
\text { engineers }\end{array}$ & 16 & $\begin{array}{lll}\begin{array}{l}\text { Construction } \\
\text { material }\end{array} & \text { skills } & \text { training } \\
\end{array}$ \\
\hline 17 & $\begin{array}{l}\text { Mechanical } \\
\text { engineers }\end{array}$ & 17 & Management skills \\
\hline 18 & $\begin{array}{l}\text { Electrical } \\
\text { engineers }\end{array}$ & 18 & ICT skills \\
\hline 19 & ICT experts & 19 & $\begin{array}{l}\text { Scientific skills and technical } \\
\text { knowledge }\end{array}$ \\
\hline 20 & $\begin{array}{l}\text { Researchers and } \\
\text { developers }\end{array}$ & 20 & Leadership skills \\
\hline 21 & $\begin{array}{ll}\begin{array}{l}\text { Supply } \\
\text { managers }\end{array} & \text { chain } \\
\end{array}$ & 21 & Teamwork skills \\
\hline
\end{tabular}

\section{Scalable heuristic social media mining analysis}

To increase the data repository, we have extended the social media analysis, by creating an implementation of a social media crawler that has retrieved, also friends and followers activity based on the list of accounts presented in Table I. We have applied a similar analysis on the database of 40 million tweets, filtered by the same expressions/queries. We have filtered around 15.000 tweets, that resulted in a set of 30 new skills and roles, outlined in the tables below.

When applying analysis on the central concept of "roles", numerous skills and roles have been identified. An improvement to the previous analysis was the exclusion of "neutral terms"' and linking words which has led to improved accuracy in results and increased list of skills and roles (see Table III).
For the determination of skills, analysis has been conducted by utilising the central concept 'skills', which led to relevant results and an increased list of skills.

For the 'training' key concept analysis, a large set of dependencies have been determined which improved the identification of skills and roles but also provided new insights for the main interests and directions that are now active in the field of BIM for energy efficiency.

TABLE III. CONSOLIDATED LIST OF ROLES AND SKILLS FROM SOCIAL MEDIA

\begin{tabular}{|c|c|c|c|}
\hline No. & Roles & No. & Skills \\
\hline 1 & Architect & 1 & IoT, ICT \\
\hline 2 & Energy Analyst & 2 & Analytic tools \\
\hline 3 & Advisory Roles & 3 & $\begin{array}{l}\text { Negotiation, social, Building } \\
\text { the bridge between the } \\
\text { worlds of education and } \\
\text { work }\end{array}$ \\
\hline 4 & $\begin{array}{l}\text { Construction } \\
\text { Managers }\end{array}$ & 4 & $\begin{array}{l}\text { Timber frame construction, } \\
\text { Educational game } \\
\text { construction, Solar panels }\end{array}$ \\
\hline 5 & $\begin{array}{ll}\text { Data } & \text { Protection } \\
\text { Officers } & \end{array}$ & 5 & $\begin{array}{ll}\text { Skills acquired } & \text { through } \\
\text { lifelong } & \text { learning } \\
\text { programmes } & \\
\end{array}$ \\
\hline 6 & Designers & 6 & Construction, IoT, ICT \\
\hline 7 & $\begin{array}{ll}\text { Digital } & \text { energy } \\
\text { economist } & \end{array}$ & 7 & Negotiation, social skills \\
\hline 8 & $\begin{array}{ll}\text { Senior } & \text { Sales } \\
\text { Advisors } & \end{array}$ & 8 & 4D simulation \\
\hline 9 & $\begin{array}{l}\text { Energy procurement } \\
\text { consultants }\end{array}$ & 9 & Augmented reality \\
\hline 10 & Finanancial analysts & 10 & Automation skills \\
\hline 11 & HMI Operator & 11 & Construction skills \\
\hline 12 & $\begin{array}{l}\text { Human resources for } \\
\text { Big Data professions }\end{array}$ & 12 & Cooperation skills \\
\hline 13 & $\begin{array}{l}\text { Information } \\
\text { coordinator } \quad \& \\
\text { information } \\
\text { facilitator }\end{array}$ & 13 & Coordination skills \\
\hline 14 & $\begin{array}{l}\text { Construction-focused } \\
\text { ICT specialists }\end{array}$ & 14 & Data science skills \\
\hline 15 & $\begin{array}{l}\text { Nanotechnology ICT } \\
\text { specialists }\end{array}$ & 15 & Digitisation in construction \\
\hline 16 & $\begin{array}{lr}\begin{array}{l}\text { Supervisors } \\
\text { construction } \\
\text { using BIM }\end{array} & \text { in } \\
\end{array}$ & 16 & Digital \& urban skills \\
\hline 17 & Technicians & 17 & Entrepreneurial skills \\
\hline 18 & Senior managers & 18 & Energy harvesting \\
\hline 19 & Aerospace engineer & 19 & Energy law \\
\hline 20 & $\begin{array}{lr}\text { Architecture } & \& \\
\text { construction } & \text { project } \\
\text { manager } & \end{array}$ & 20 & Energy performance \\
\hline 21 & Building professional & 21 & Energy storage \\
\hline 22 & Chemical engineer & 22 & Energy transition \\
\hline 23 & $\begin{array}{l}\text { Communication } \\
\text { officer }\end{array}$ & 23 & E-learning skills \\
\hline 24 & $\begin{array}{ll}\text { Data } & \text { protection } \\
\text { officer } & \end{array}$ & 24 & $\begin{array}{lll}\begin{array}{l}\text { Energy } \\
\text { making }\end{array} & \text { policy } & \text { decision } \\
\end{array}$ \\
\hline
\end{tabular}




\begin{tabular}{|c|c|c|c|}
\hline 25 & Designer & 25 & Engineering skills \\
\hline 26 & Energy engineer & 26 & ICT skills \\
\hline 27 & $\begin{array}{l}\text { Environmental } \\
\text { scientist }\end{array}$ & 27 & Labour work skills \\
\hline 28 & $\begin{array}{l}\text { Government affairs } \\
\text { manager }\end{array}$ & 28 & Leadership skills \\
\hline 29 & $\begin{array}{l}\text { Information } \\
\text { facilitator }\end{array}$ & 29 & Low - zero energy buildings \\
\hline 30 & $\begin{array}{l}\text { Market acquisition } \\
\text { manager }\end{array}$ & 30 & Management skills \\
\hline
\end{tabular}

\section{DISCUSSION}

This paper seeks to identify and target new recruits for skilled trades and the professions in the construction industry by addressing training and development needs on a more strategic basis. The transient nature of the workforce and the changing nature of the construction industry made BIM training and education of the construction workforce particularly important.

The analysis demonstrated that an organisation in the field of BIM for energy and construction needs to pay attention to organisational and human skills involved in BIM process and adopt a continuous improvement approach to change. From the related work, it was determined that the role of these BIM roles and skills concepts is often neglected in the existing BIM studies. For example, all the studies reported the urgent need for training to use the existing BIM skills and competencies efficiently and utilise the full potential of the new system to increase productivity and improve quality. Also, the analysis of the research results showed that there is a potential danger of resistance to change which might constrain the change process. Consequently, the analysis we have conducted has shown a need to involve the endusers more closely in the decision-making process as well as in the implementation process.

A challenge has been presented to the accuracy of the collected tweets, as the collected tweets needed to have been as comprehensive and representative as possible for the construction training needs. As future work, collection of tweets from alternative sources of training needs across the industry is planned.

Our approach has started from the social media content analysis that identified, analysed, and assessed construction sector stakeholders' requirements for BIM training to ensure engagement with energy management in construction. From this social media, a complex analysis process was conducted to determine the skills and roles of BIM for energy efficiency. This paper aims to determine skills and roles which will inform the training process to greatly educate the community of users in the field of BIM and promote energy-efficient practices among companies and users.
Skills and competencies need to be developed to actively promote the widespread use of BIM-based transversal and multidisciplinary collaborative approaches and methods in the European (and beyond) construction industry, currently facing fragmentation and inadequate training resources. Training and education programs will raise awareness of stakeholders in the construction value chain about (a) environmental challenges, (b) current and future sustainability scenarios, and (c) energy efficiency targets and governments agendas, with a view of delivering informed built environment interventions across lifecycle underpinned by an effective BIM-based training Europe-wide agenda.

\section{CONCLUSION}

This paper conducts intensive analysis for identification of skills and roles for the processes related to BIM for energy efficiency. From the evaluation of the process, we have implemented an analysis scenario for Twitter data as a mean to infer knowledge and capture new BIM skills and roles.

The findings show that the evaluation employed for skills and roles identification can help to understand better the training requirements and identify gaps for the BIM training with further impact on energy practices and BIM implementation programs in Europe. The evaluation of the stage referred to as "social media analysis" showed that the resulted list of roles and skills is novel and can bring new insights into the process of BIM training and education. The new technological capabilities proposed by social media gave a unique opportunity to re-engineer and improve the existing methodology and to extend on the existing state of knowledge for BIM in energy efficiency. In addition to the acknowledged role of social media, the analyses have suggested that some organisational characteristics have to change to support the implementation of the new BIM processes leading to the conclusion that BIM is a dynamic process that cannot be captured with traditional analysis methods. The analysis has also shown that this stage of skills and roles identification is crucial due to the number of supporting concepts which play a major role in the BIM process characterisation. Therefore, a holistic methodology is required for the assessment of BIM with associated competencies and training programmes.

One of the findings of our study was that the roles, responsibilities and skills are not static but are dynamic and they reflect the evolution of technology, as well as the educational level of the workforce. Therefore, it is essential to have a mechanism in place, as described in the methodology section, that enables us to refresh and adapt the roles and skills. 


\section{ACKNOWLEDGEMENT}

This work is part of the EU H2020 BIMEET Project: "BIMbased EU-wide standardized qualification framework for achieving energy efficiency training."

\section{VIII.REFERENCES}

[1] Rezgui, Y., Wilson, I.E., Miles, J., Hopfe, C.J.: Federating information portals through an ontology-centred approach: A feasibility study. Adv. Eng. Informatics. 24, 340-354 (2010). doi:10.1016/j.aei.2010.02.001

[2] Yacine Rezgui, Christina J. Hopfe, Chalee Vorakulpipat. "Generations of knowledge management in the architecture, engineering and construction industry: An evolutionary perspective", Advanced Engineering Informatics, 2010

[3] Löwnertz, K.: Change and exchange: electronic document management in building design, (1998)

[4] Boddy, S., Rezgui, Y., Cooper, G., Wetherill, M.: Computer integrated construction: A review and proposals for future direction. Adv. Eng. Softw. 38, 677-687 (2007). doi:10.1016/j.advengsoft.2006.10.007

[5] Hjelt, M., Björk, B.-C.: Experiences of EDM usage in construction projects. (2006)

[6] Giannini, F., Monti, M., Biondi, D., Bonfatti, F., Monari, P.D.: A modelling tool for the management of product data in a co-design environment. Comput. Des. 34, 1063-1073 (2002). doi:10.1016/S00104485(01)00188-9

[7] Vorakulpipat, C., Rezgui, Y.: Value creation: The future of knowledge management (2008). doi: 10.1017/S0269888908001380

[8] Industrial automation systems and integration - Product data representation and exchange - Part 1: Overview and fundamental principles. ISO (1994)

[9] Björk, B.-C.: Basic structure of a proposed building product model. Comput. Des. 21, 71-78 (1989). doi:10.1016/0010-4485(89)90141-3

[10] Building information modelling - experts' views on standardisation and industry deployment. Adv. Eng. Informatics. 22, 271-280 (2008)

[11] Pinheiro, Sergio, et al. "MVD based information exchange between BIM and building energy performance simulation." Automation in Construction 90 (2018): 91-103.

[12] Building Information Modeling: A Strategic Implementation Guide for Architects, Engineers, Constructors, and Real Estate Asset Managers. Wiley, Hoboken, N.J (2009)

[13] Beach, T.H., Rezgui, Y., Li, H., Kasim, T.: A rule-based semantic approach for automated regulatory compliance in the construction sector (2015). doi: 10.1016/j.eswa.2015.02.029

[14] The BuildingSMART Handbook, (2010), accessed $05^{\text {th }}$ of February, 2019, https://www.buildingsmart.org

[15] Eastman, C.M.: BIM handbook: a guide to building information modelling for owners, managers, designers, engineers and contractors. Wiley (2011)

[16] Manish Yakami, Vishal Singh, Sunil Suwal. "Chapter 32 What Do Students and Professionals Think of BIM Competence?", In: Ríos J., Bernard A., Bouras A., Foufou S. (eds) Product Lifecycle Management and the Industry of the Future. PLM 2017. IFIP Advances in Information and Communication Technology, vol 517. Springer, Cham

[17] Fass, D.: Metadata of the chapter that will be visualised in SpringerLink Correlating Unlabeled Events from Cyclic Business. (2016). doi:10.1007/978-3-319-64861-3

[18] EUR-Lex Access to European Union law: Communication from the Commission to the European Parliament, the Council, the European
Economic and Social Committee and the Committee of the Regions on the Sustainable Consumption and Production and Sustainable Industrial Policy Action Plan, accessed 05 $5^{\text {th }}$ of February, 2019, https://eurlex.europa.eu/legal-content/EN/TXT/?uri=celex\%3A52008DC0397

[19] The European Parliament and the Council of the, European Union: Directive 2010/31/EU of the European Parliament and of the Council of 19 May 2010 on the energy performance of buildings. (2010)

[20] Bottaccioli, L., Aliberti, A., Ugliotti, F., Patti, E., Osello, A., Macii, E., Acquaviva, A.: Building Energy Modelling and Monitoring by Integration of IoT Devices and Building Information Models. 2017 IEEE 41st Annu. Comput. Softw. Appl. Conf. 914-922 (2017). doi:10.1109/COMPSAC.2017.75

[21] Succar, B., Sher, W., Williams, A.: An integrated approach to BIM competency assessment, acquisition and application. Autom. Constr. 35, 174-189 (2013). doi:10.1016/J.AUTCON.2013.05.016

[22] Mohd, S., Ahmad Latiffi, A.: Building Information Modeling (BIM) application in construction planning. (2013)

[23] Wu, W., Issa, R.R.A.: Key Issues in Workforce Planning and Adaptation Strategies for BIM Implementation in Construction Industry. In: Construction Research Congress 2014. pp. 847-856. American Society of Civil Engineers, Reston, VA (2014)

[24] Meziane, F., Rezgui, Y. A document management methodology based on similarity contents (2004). doi: 10.1016/j.ins.2003.08.009

[25] Rahman, R.A., Alsafouri, S., Ayer, S.K.: Comparing Building Information Modeling Skills of Project Managers and BIM Managers Based on Social Media Analysis. Procedia Eng. 145, 812-819 (2016). doi:10.1016/J.PROENG.2016.04.106

[26] Dossick, C.S., Lee, N., Foleyk, S.: Building Information Modeling in Graduate Construction Engineering and Management Education. In: Computing in Civil and Building Engineering (2014). pp. 2176-2183. American Society of Civil Engineers, Reston, VA (2014)

[27] Barison, M.B., Santos, E.T.: The Competencies of BIM Specialists: a Comparative Analysis of the Literature Review and Job Ad Descriptions. (2011)

[28] Succar, B., Sher, W., Williams, A.: Measuring BIM performance: Five metrics. Archit. Eng. Des. Manag. 8, 120-142 (2012). doi:10.1080/17452007.2012.659506

[29] Petri, I., Beach, T., et al. 2014. Engaging construction stakeholders with sustainability through a knowledge harvesting platform. Computers in Industry 65(3), pp. 449-469, doi.org/10.1016/j.compind.2014.01.008

[30] Conrad Boton, Sylvain Kubicki, Gilles Halin. Designing adapted visualisation for collaborative 4D applications. Automation in Construction, Volume 36,2013, Pages 152-167, doi.org/10.1016/j.autcon.2013.09.003

[31] Yuce, B. and Rezgui, Y. 2017. An ANN-GA Semantic Rule-Based System to Reduce the Gap Between Predicted and Actual Energy Consumption in Buildings. IEEE Transactions on Automation Science and Engineering 14(3), pp. 1351-1363, accessed $05^{\text {th }}$ of February, 2019, http://ieeexplore.ieee.org/document/7317804/

[32] CIOB: A BIM Mandate lesson from Denmark, accessed $05^{\text {th }}$ of February, 2019, http://www.bimplus.co.uk/people/bimma4ndate-lesso4nden7mark/

[33] Federal Ministry of Transport and Digital Infrastructure: BMVI, accessed $05^{\text {th }} \quad$ of $\quad$ February, 2019 , https://www.bmvi.de/SharedDocs/DE/Pressemitteilungen/2017/009dobrindt-bimgipfel.html?nn=214506

[34] The European Commission: Construction Sector Improving the human capital basis. 1-65 (2017) , accessed $05^{\text {th }}$ of February, 2019, https://ec.europa.eu/docsroom/documents/26206/attachments/1/translati ons/en/renditions/pdf 